\title{
Composition and Rheological Properties of Flour and Dough from Genetically Modified Wheat (Triticum aestivum L.) Hi-Line 111
}

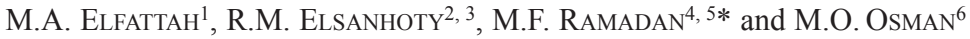 \\ ${ }^{1}$ Food Technology Research Institute, Agriculture Research Center, Giza, Egypt \\ ${ }^{2}$ Department of Industrial Biotechnology, Institute of Genetic Engineering and Biotechnology, \\ Sadat City University, Sadat City, Egypt \\ ${ }^{3}$ MAX Rubner Institute, Federal Research Institute of Nutrition and Food, Detmold, Germany \\ ${ }^{4}$ Department of Biochemistry, Faculty of agriculture, Zagazig University, 44519 Zagazig, Egypt \\ ${ }^{5}$ Deanship of Scientific Research, Umm Al-Qura University, Makkah, Saudi Arabia \\ ${ }^{6}$ Department of Biochemistry, Faculty of Agriculture, Cairo University, Cairo, Egypt
}

(Received 12 December 2015; Accepted 15 February 2016; Communicated by F. Békés)

The main objective of this work was to evaluate the composition, nutritional, physical and rheological properties of wheat flour and dough from genetically modified wheat (Triticum aestivum L.) Hi-Line 111 (GMW) compared to conventional wheat (non-GMW). Analyses were conducted to measure the proximate chemical composition with references to $18 \mathrm{com}$ ponents including total solid, protein, lipids, crude fiber, ash, carbohydrate, minerals, amino acids, and fatty acids. In addition, physical and rheological properties such as water absorption, arrival time, dough development time, stability value, dough weakening value, extensibility of dough, resistance to extension, and ratio of resistance/extensibility were evaluated. The results showed that there were no significant differences between GMW and non-GMW in terms of chemical composition. Results revealed the presence of saturated and unsaturated fatty acids wherein there were no significant differences between GMW and its counterpart in the levels of fatty acids. In addition, there were no significant differences on the levels of amino acids. In addition, there were no significant differences between the GMW and non-GMW in the physical and rheological properties. From these results, it can be concluded that GMW Hi-Line 111 is confirmed to have nearly the composition and rheological properties as non-GMW.

Keywords: GMO, compositional analysis, biochemical analysis, substantial equivalence, rheological properties

*Corresponding author; E-mail: hassanienmohamed@yahoo.com; Phone: +2 0552320282 or +2 055 2313940; Fax: +2 0552287567 or +20552345452 


\section{Introduction}

Agricultural genetic engineering has opened a new avenue in the development of genetically modified (GM) plants with enhanced insect or herbicide resistance, abiotic stress tolerance, or nutritional improvement (Sthrestha et al. 2008; Raybould et al. 2012). With the worldwide commercialization and rapid increase in genetically modified organisms (GMO), numerous transgenic crops are being developed with modified trait involving multiple genes for more and greater characteristics with the expectation of solving problem such as disease, weed management, enhancing production efficiency and improving functional properties (Shin et al. 2013).

Genetic engineering introduces new genes, new genetic information, and new constituents into the cells of a food-producing organism. These new proteins could themselves cause allergies or be toxic (Taylor 1997). Alternatively, they could alter the cellular metabolism of the food-producing organism in unintended and unanticipated ways, and, in turn, these alternations in metabolism could cause allergens or toxins to be produced in food. Another possibility is that the food-producing organism might fail to make some important vitamins or nutrients. Consequently, the genetically engineered food would lack important nutrients that are normally present in the corresponding non-genetically engineered food. In addition genetic manipulations can cause unexpected and unintended adverse changes in the composition or characteristics of foods, food ingredients and food additives, thereby rendering foods unsafe health-damaging (Elsanhoty et al. 2004, 2013; Herman et al. 2009).

Some studies assessed the safety of GM plants and report some changes in serum chemistry due to GM foods utilization (Hammond et al. 2004, 2006; Elsanhoty et al. 2004, 2006). It was observed a few statistically significant differences between rats fed on GM corn (MON 810) and its control as well as GM potato Spunta and its control (Elsanhoty et al. 2004, 2006). Therefore, assessments of food safety and nutritional value of both human food and animal feed derived from GM crops require detailed knowledge of the plant composition.

Consumer concerns regarding GM products relate mostly to unanticipated health impacts that may arise from direct consumption of GM products or products from animals fed GM ingredients (Dona and Arvanitoyannis 2009; Martinez-Povida et al. 2009). The nutritional quality changes by insertion of the desired gene also is essential, but at the same time, nutritional assessment of GM crops is an important aspect of biosafety evaluation, as recommended by food safety regulatory agencies (Chassy 2010). There are some of GM crops authorized for use as food or feed in many countries based on those countries' criteria for safety assessment. Consumers have demanded appropriate information and labeling for foods derived from GM crops. Thus, various labeling systems have been introduced for GM foods (Oguchi et al. 2010). Pressure from consumers and public demand has led many countries to require labeling for the presence of GMOs in foods and sensitive detection methods for GM foods and feeds (Yoke-Kqueen et al. 2011; Ramadan and Elsanhoty 2012; Elsanhoty et al. 2013; Castigliego et al. 2015; Turkec et al. 2016). 
Many of literatures mentioned that there are many risk assessments for GM foods, wherein 'substantial equivalence' concept was introduced by the Food and Agriculture Organization (FAO) and World Health Organization (WHO) in the early 1990s. In 1993 the Organization for Economic Co-operation and Development (OECD) developed the concept of substantial equivalence (Gayen et al. 2013). The technique was focused on comparative assessment thorough evaluation of crop composition (Elsanhoty et al., 2004; Herman et al. 2009).

The utilization of GM crops for food, feed and processing was the subject of intense debate since their initial introduction into the global market (Domingo and Bordonaba 2011). Wheat and rice are the most important cereal crops grown in the world today (Pimentel 2009). Wheat is the principal source of energy, and dietary fiber for a major portion of the world's population (Abdel-Aal and Hucl 2002). In addition to its basic caloric value, wheat, with its high protein content, is the single most important source of protein in the human diet (FAO 2001).

The genetically modified wheat (Triticum aestivum L.) Hi-Line 111 (GMW), have been transformed with plasmid pAB1 harboring the full-length HVA1 cDNA (Hong et al. 1988; Lanning et al. 1992) to transform immature GMW Hi-Line 111 cv. Hi-Line embryos (Sivamani et al. 2000). This work aimed to study the compositional analysis of GMW and non-GMW line as well as the physical and rheological properties of the dough. GMW under investigation was developed during the scientific cooperation between Agriculture genetic engineering research institute (Giza, Egypt) and Department of Crop Science, North Carolina State University (USA) by introducing of the barley HVA1 gene. Encoding a member of the group 3 late embryogenesis abundant (LEA) proteins has been introduced into spring wheat cv. Hi-Line to determine its effect on drought tolerance to improve biomass productivity and water use efficiency under water deficit conditions in GMW constitutively expressing the barley HVA1 gene (Sivamani et al. 2000).

\section{Materials and Methods}

\section{Materials}

GMW Hi-Line 111 and its conventional non-GMO control line used in this study were cultivated and harvested under the same conditions in the Agricultural Genetic Engineering Research Institute (AGERI), Agriculture Research Center (ARC) at Giza (Egypt). Genetic modification in GMW Hi-Line 111, have been transformed with the plasmid pAB1 (Fig. S1*) harboring the full-length HVA1 cDNA (Hong et al. 1988; Lanning et al. 1992) to transform immature T. aestivum L. cv. Hi-Line embryos, as described by Sivamani et al. (2000). A $1.1 \mathrm{~kb} E c o$ RI fragment containing HVA1 cDNA was filled using Klenow fragment and blunt-end ligated to the previously digested and filled BamHI site of pAHC17 to obtain pRQ42 (Hong et al. 1988; Christensen and Quail 1996). A $2.09 \mathrm{~kb}$ HindIII fragment was obtained from pBARGUS which contains the bar gene driven by the CaMV 35S promoter, with the maize $A d h 1$ intron 1 in the 5\% non-translated region

\footnotetext{
*Further details about the Electronic Supplementary Material (ESM) can be found at the end of the article.
} 
and the NOS terminator (De Block et al. 1987; Fromm et al. 1990). This fragment was ligated with HindIII-digested pRQ42 to obtain pAB1. The bar gene encodes phosphinothricin acetyl transferase which inactivates phosphinothricin (De Block et al. 1987). The genetic elements in GM line of Triticum aestivum was explained in Fig. S1.

\section{Compositional analysis}

Both GMW and non-GMW lines were analyzed for moisture, fiber, protein, ash, and minerals according to the AOAC (2005). Amino acids composition was analyzed according to Block et al. (1958). Total lipids were extracted according to Bligh and Dyer (1959). The profile of fatty acid was determined by GLC equipped with flame ionisation detector (FID). Trimethyl sulfonium hydroxide (TMSH) was used for preparation of fatty acid methyl esters according to the procedure of (Arens et al. 1994). A Shimadzu system, model GC-14A fitted with an sp-2380 fused silica capillary column $(30 \mathrm{~m} \times 0.25 \mathrm{~mm} \times 0.2$ $\mathrm{mm}$; Supelco Inc., Bellefonte, PA, USA) was used. The temperature of injection port and detector was set up at $250{ }^{\circ} \mathrm{C}$. The oven temperature was increased from $110{ }^{\circ} \mathrm{C}$ to $175^{\circ} \mathrm{C}$ at a rate of $5^{\circ} \mathrm{C} / \mathrm{min}$.

\section{Rheological properties of dough}

Farinograph test was carried out by farinograph (Brabender, Duisburg, Germany) according to the standard AACC methods (2000). The elastic properties of the dough were studied using extensograph (Brabender, Duisburg, Germany) according to the standard AACC methods (2000). Wet, dry gluten and gluten index of wheat flour were measured according to the approved AACC methods (AACC 2000).

\section{Statistical analysis}

Compositional data are presented as means \pm confidence intervals $(p<0.05)$. Means are considered as statistically significantly different if their confidence intervals are not overlapping.

\section{Results}

\section{Compositional analysis}

Compositional results were compared to results reported for wheat grains and differences between the wheat lines were assessed for statistical significance $(p<0.05)$. Contents of proximate are presented in Table $\mathrm{S} 1$. There were no statistically significant differences between GMW and non-GMW observed for total protein, ash, crude fiber and total carbohydrate content. However, GMW exhibited statistically significant higher contents of total fat, and statistically significant lower moisture content. 


\section{Composition of minerals}

The comparison of the minerals levels in tested flour samples revealed some differences in the minerals content (Table S2). The iron (Fe) content in non-GMW (8.03 mg/100 g) was higher than in GMW (7.07 mg/100 g). Zn content for non-GMW (9.54 mg/100 g) was lower than GMW (10.0 mg/100 g). Mn content for non-GMW (7.7 mg/100 g) was lower than in GMW $(8.2 \mathrm{mg} / 100 \mathrm{~g})$. Concerning the minerals under study, there were generally no statistically significant differences observed between non-GMW and GMW. However, GMWt exhibited statistically significant lower contents of Mg $(-15 \%)$.

\section{Amino acids composition}

The profiel of 17 amino acids in GMW was comparable to those of the control line grains (Table S3). These results were either within published literature ranges or within the range of historical conventional control values determined in previous studies (Anjum et al. 2006). Differences between the lines were assessed for statistical significance $(p<0.05)$. There were no statistically significant differences between transgenic and parental wheat observed for essential amino acids and some of non-essential amino acids. However, GMW exhibited statistically significant higher contents of glutamic acid $(+6.7 \%)$, and a statistically significant lower content of aspartic acid $(-17 \%)$, and glycine $(-8 \%)$.

\section{Fatty acids composition}

The fatty acid profile of non-GMW and GMW is presented in Table S4. Capric, lauric, myristic, palmitic, palmitoleic, stearic, oleic, linoleic, linolenic, arachidic, gadoleic, and behenic acids were identified. As can be noted, the predominant fatty acids were linoleic and oleic as unsaturated fatty acids as well as palmitic and behenic as saturated fatty acids.

\section{Rheological properties of dough}

Wet gluten, dry gluten and gluten index

Gluten is a plastic-elastic protein fraction of wheat flour responsible for physical dough properties. The wet gluten quality in the analyzed samples of wheat flour was measured by the glutomatic apparatus. Wet gluten content was $24.5 \%$ for flour samples from nonGMW whiel GMW had higher wet gluten (26.03\%). On the other hand, dry gluten content (Table S5) of the tested flour samples was 9.22 and $9.98 \%$ for non-GMW and GMW flour samples, respectively.

\section{Farinograph and extensograph}

Rheological properties of dough during the mixing process are evaluated to understand and predict the behavior of flour in experimental baking tests. The farinograph provides checks for uniformity and allow for predictions of baking functionality. So it is used to 
determine the water absorption of flour (\%), arrival time (min), dough development time (min), dough stability (min) and dough weakening (B.U.). Farinograph curve gives two important physical properties of flour, the water absorption (i.e., the amount of water required for a dough to reach define consistency), and a general profile of the mixing behavior of the dough (dough development time and stability). Farinograms were obtained for experimental flour samples as illustrated in Fig. S2 and the obtained results from farinograms were presented also in Table S6. The data revealed that water absorption was $62.5 \%$ of non-GMW, while it was $64.5 \%$ for GMW flour sample. On the other hand, arrival time ranged from 0.5 to $1.5 \mathrm{~min}$, dough development time ranged from 1.5 to 2.0 min, while dough stability showed that the stability values reached more than 12 and 8.5 min in GMW and non-GMW flour samples, respectively. These results may be due to the higher protein content in flour samples of GMW. The results of extensograph parameters of tested wheat flour samples are summarized in Table S7 and presented in Fig. S3. Extensibility of dough recorded 160 and $165 \mathrm{~mm}$ for GMW and non-GMW flour samples, respectively. Data in Table S7 shows that GMW and non-GMW samples recorded 440 and $410 \mathrm{BU}$, respectively. The R/E values of dough made from GMW and non- GMW samples were 2.75 and 2.49 , respectively. Regarding the strength of dough, it was found that dough made from GMW recorded $132 \mathrm{~cm}^{2}$ compared to non-GMW which recorded $125 \mathrm{~cm}^{2}$.

\section{Discussion}

Safety assessment studies conducted on GM wheat was based on the application of the principle of substantial equivalence, which has been adopted by leading international food and regulatory bodies including the World Health Organization (WHO 1991, 1995). According to this principle, a new food or food derived from a GM crop was found to be substantially equivalent to its conventional counterpart as safe as the food or feed from the conventional plant variety. Substantial equivalence may be classified in three different ways; (i) substantially equivalent: this implies complete biochemical identity between the novel food and the existing food, expect for the properties conferred by the introduced gene; (ii) substantial equivalent expects for some defined traits wherein the novel food is substantially equivalent to its traditional counterpart, expect for certain identifiable and defined differences, such as that the differing properties would require specific safety studies and (iii) lack of equivalence wherein the novel food differs from the traditional products in multiple undefined respects, such that the novel food would need to be thoroughly examined to assess its safety, before accepted or rejected (Momma et al. 2000).

The compositional analysis of GM crops has continued to be an important part of the overall evaluation in the safety assessment program (Elsanhoty et al. 2004; Brune 2013; Rayan and Abbott 2015). It is important to assess whether the composition of GM wheat is substantially equivalent to or has significant differences from conventional wheat. The food safety assessment of GMW in this work consists of evaluation of chemical profile of GMW and non-GMW as well as characterization of rheological traits of flour and dough from both cultivars. 
The results of chemical composition are in agreement with Han et al. (2005) who reported that, the lipid content in parental rice was slightly higher and moisture was slightly lower than in GM rice. Also, Schröder et al. (2007) reported that GM rice exhibited a statistically significant higher protein content $(+8 \%)$ and a statistically significant lower lipids content $(-18 \%)$. The obtained results also are in agreement with the results published by Elsanhoty et al. (2004) who found that there were no significant differences between GM potato Spunta (G2 and G3), and potato Spunta control in the chemical composition including levels of glycoalkaloids, protease inhibitor activity and total phenol. Our results were also in agreement with previous results obtained by Wu et al. (2006); He et al. (2008); Appenzeller et al. (2009); Rayan and Abbott (2015), who reported that there are no significant differences between the GM verities of corn and potato and their counterpart. Anjum et al. (2006) and Jiang et al. (2008) reported that, protein content ranged from 13.07 to $19.21 \%$. High content of fiber was found in GM wheat $(2.71 \%)$, compared to the non-GM wheat $(2.63 \%)$. Both crude fiber and ash content in wheat are related to the amount of bran in the wheat. The carbohydrate levels were high in non-GM wheat $(69.9 \%)$ in comparison with GM wheat (69.53\%).

Minerals are very important and essential ingredients of diet that required for normal metabolic activities of tissues (Hambidge et al. 2004). The zinc (Zn) plays a vital role in guarding against diseases and infection. There are 156 enzymes that require zinc for their functioning. It has long been known that growth and sexual maturity depend on zinc. The recommended daily allowance of zinc is $15 \mathrm{mg}$ (Hambidge et al. 2004). Manganese (Mn) is an inorganic nutrient involved in many important enzymes. Our results are in agreement with Ridley et al. (2002); Elsanhoty et al. (2004); Poulsen et al. (2007); Rayan and Abbott (2015) who reported that there were no statistically significant differences in the content of $\mathrm{Ca}, \mathrm{Mg}$, and $\mathrm{Zn}$ in non-GM corn and GM corn events (NK603, MON88017, MON810 and MON89034, MON88017). However, GM rice exhibited significant higher contents of $\mathrm{Fe}(+144 \%), \mathrm{Mg}(+15 \%)$, phosphorous $(+19 \%)$ and potassium $(+31 \%)$, as well as lower copper content $(-19 \%)$. Schröder et al. (2007) reported that no statistically significant differences were observed between the transgenic and the parental rice in the contents of $\mathrm{Ca}, \mathrm{Mg}$, phosphorous and potassium. However, the transgenic rice exhibited significant lower contents of copper $(-57 \%)$, Fe $(-27 \%), \mathrm{Mg}(-38 \%)$, molybdenum $(-33 \%)$, and zinc $(-30 \%)$. The results also are in agreement with the published literature data and ranges of the historical conventional control values determined in previous studies (Elsanhoty et al. 2006).

The results of amino acids profile were in agreement with the obtained by Schröder et al. (2007) who reported the transgenic rice exhibited significant higher contents of all amino acids except cystine and proline. In particular, levels of arginine and histidine were very high in GM rice compared to non-GM rice. The obtained results were also in agreement with Poulsen et al. (2007) who found that GM rice contained higher contents of almost all amino acids.

The results of fatty acids profile are in agreement with those of Prabhasankar and Haridas (2001) who reported that, palmitic acid was the major saturated fatty acid and linoleic was the major unsaturated fatty acids in strong and weak wheat varieties. The content of 
12 fatty acids in GMW was comparable to those of the control line grains. The results were within published literature ranges and within the range of historical conventional control values determined in previous studies (Elsanhoty et al. 2004; Ramadan and Elsanhoty 2012; Rayan and Abbott 2015). There were a statistically significant differences observed for fatty acid distribution (Table S4). A statistically significantly higher proportion of palmitic, linoleic and linolenic acid was found for the transgenic wheat $(+9 \%,+0.8 \%$ and $+51 \%$, respectively), whereas the parental wheat exhibited a statistically significant higher proportion of lauric, myristic, palmitoleic, stearic, oleic and behenic acid $(+31 \%,+27 \%,+37 \%,+26 \%,+5 \%$, and $+2 \%$, respectively). On the other hand, there were two fatty acids not detected in GMW. There were no statistically significant differences between transgenic and parental wheat observed for gadoleic acid. The results are in agreement with the obtain results by Schröder et al. (2007); Elsanhoty et al. (2006); Rayan and Abbott (2015) who reported no significantly differences between transgenic and parental potato spunta, GM corn Bt176, and genetically modified corn events (NK603, MON88017, MON810 and MON89034, MON88017).

Concerning the rheological properties of dough, it has been generally accepted that any increase in the total protein content of the flour results in an increase in gluten content (Perten et al. 1992), which coincide with present study where protein percentage in GMW was higher than the percentage in non-GMW, although this increase was not significant. The results are consistent with those reported by Kucek et al. (2015) who found that, wet gluten content of different varieties of wheat was ranged from 21.3 to $32.3 \%$, while dry gluten content was ranged from 8.44 to $11.7 \%$. Concerning to the gluten index value, it was recorded 88.9 and $95.05 \%$ for non-GMW and GMW flour samples, respectively. These results are in harmony with those reported by Ferrari et al. (2014); Oikonomou et al. (2015), who reported that gluten index values of different wheat flours were ranged from 50.0 to $99.3 \%$ depending on the varieties.

Our results are in line with the results obtained by Ferrari et al. (2014); Oikonomou et al. (2015), who reported that, the mixing time stability gives some indication of flour's tolerance to mixing. Flour with long times are stable to mixing than flour with short times. Flour with low protein content is known to have short stability times. However, the data of the dough weakening revealed that non-GMW flour sample had higher value (80 B.U.), whereas the GMW flour sample recorded zero of dough weakening value. This finding is in agreement with Ertugay et al. (2007); Ferrari et al. (2014); Oikonomou et al. (2015) who demonstrated that the water absorption is a function of protein content but other factors, especially starch damage during milling, also affect water absorption. Variations in dough stability, and other farinogram measurements indicated clear differences in gluten quality of the wheat samples. Such variation could be due to flour strength, since dough stability is an important index for flour strength which is based on the quality and quantity of dough protein that could capture sufficient amount of produced gas during fermentation.

Our results agree with Hruskova et al. (2001) and Vaiciulyte-Funk et al. (2015), who stated that the genetically engineering and organic culture affected of dough properties especially in extensibility. Resistance to extension is usually defined as the ability of the 
dough to regain its shape after extension. It depends on the amount of glutenin in the dough.

We can conclude that GMW with the plasmid pAB1 harboring the full-length $H V A 1$ cDNA was similar in the chemical composition to non-GMW. Therefore, the safety of the GMW Hi-Line 111 may be guaranteed by substantial equivalence according to the abovementioned classification. The introduction of this combination of genetic elements in wheat had no adverse effect on the whole chemical composition tested. On the other hand, there were no significant differences between GMW and non-GMW in terms of gluten index as well as physical and rheological properties of wheat flour dough. Based on the obtained results and on the basis of the principles of substantial equivalence (as proposed by WHO and FAO), it can be concluded that the composition of the GMW HiLine 111 is substantially equivalent to that of the conventional control line.

\section{References}

AACC 2000. Approved Methods of the Association of American Cereal Chemists. St. Paul, MN, USA.

Abdel-Aal, E.S.M., Hucl, P. 2002. Amino acid composition and in vitro protein digestibility of selected ancient wheat's and their end products. J. Food Comp. Anal. 15:737-747.

Anjum, F.M., Zulfiqar, A., Asghar, A., Hussain, S. 2006. Use of iron as fortificant in whole wheat flour and in leavened flat breads in Developing countries. Electronic J. Environ. Agric. Food Chem. 5:1366-1370.

AOAC 2005. Official Methods of Analysis of the Association of Official Analytical Chemists International (18 $8^{\text {th }}$ ed.). Maryland, USA.

Appenzeller, L.M., Malley, L., MacKenzie, S.A., Hoban, D., Delaney, B. 2009. Subchronic feeding study with genetically modified stacked trait lepidopteran and coleopteran resistant maize grain in Sprague-Dawley rats. Food Chem. Toxicol. 47:1512-1520.

Arens, M., Schulte, E., Weber, K. 1994. Fettsäuremethylester, Umesterung mit Trimethylsulfoniumhydroxid (Schnellverfahren) [(Fatty acid methyl ester. Transesterification using trimethyl sulfonium hydroxid (a rapid method)]. Fat Sci. Technol. 96:67-68.

Belderok, B., Mesdag, H., Donner, D.A. 2000. Bread-Making Quality of Wheat. Springer. New York, USA.

Bligh, E.G., Dyer, W.J. 1959. A rapid method of total lipid extraction and purification. Canadian J. Biochem. Physiol. 37:911.

Block, R.J., Durrum, E.L., Zweig, G. 1958. A Manual of Paper Chromatography and Paper Electrophoresis. Academic Press. New York, USA.

Brune, P.D., Culler, A.H., Ridley, W.P., Walker, K. 2013. Safety of GM crops: Compositional analysis. J. Agric. Food Chem. 61:8243-8247.

Castigliego, L., Armani, A., Tinacci, L., Gianfaldoni, D., Guidi, A. 2015. Two alternative multiplex PCRs for the identification of the seven species of anglerfish (Lophius spp.) using an end-point or a melting curve analysis real time protocol. Food Chem. 166:1-9.

Chassy, B.M. 2010. Food safety risks and consumer health. New Biotechnol. 27:534-544.

Christensen, A.H., Quail, P. 1996. Ubiquitin promoter-based vectors for high level expression of selectable and/ or screenable marker genes in monocotyledonous plants. Transgenic Res. 5:213-218.

De Block, M., Botterman, J., Vandewiele, M., Dock, J., Thoen, C., Gossele, V., Rao Movva, N., Thompson, C., Van Montagu, M., Leemans, J. 1987. Engineering herbicide resistance in plants by expression of a detoxifying enzyme. EMBO J. 6:2513-2518.

Domingo, J.L., Bordonaba, J.G. 2011. A literature review on the safety assessment of genetically modified plants. Environment Inter. 37:734-742.

Dona, A., Arvanitoyannis, I.S. 2009. Health risks of genetically modified foods. Crit. Rev. Food Sci. Nutr. 49:164-175. 
Elsanhoty, R.M., Al-Turki, I.A., Ramadan, F.M. 2013. Prevalence of genetically modified rice, maize and soy in commercial food products in Kingdom of Saudi Arabia market. Appl. Biochem. Biotechnol. 171:883899.

Elsanhoty, R.M., Abdelrahman, A.A., Bögl, K.W. 2004. Quality and safety evaluation of genetically modified potato Spunta with Cry V gene: Chemical composition, determination of some toxins, antinutrients compounds and feeding study on rat. Nahrung/Food 48:13-18.

Elsanhoty, R.M., Eldesouky, A.M., Ramadan, M.F. 2006. Safety assessment of genetically modified potato Spunta: Degradation of DNA in gastrointestinal track and carry over to rat organs. J. Food Biochem. 30:556-578.

Ertugay, M.F., Kotancilar, H.G., Wehling, R.L. 2007. Determination of protein, wet and dry gluten of wheat flours by near-infrared spectroscopy. In: 2nd Int. Congress on Food and Nutrition. Istanbul, Turkey. pp. $35-46$.

FAO, FAOSTAT 2001. Agricultural database, Food and Agriculture Organisation of the United Nations (FAO) http://www.fao.org

Ferrari, C.M., Clerici, I., Maria, T.P.S., Chang, K.Y. 2014. A comparative study among methods used for wheat flour analysis and for measurements of gluten properties using the Wheat Gluten Quality Analyser (WGQA). Food Sci. Technol, Campinas. 34:235-242.

Fromm, M.E., Morrish, F., Armstrong, C., Williams, R., Thomas, J., Klein, T.M. 1990. Inheritance and expression of chimeric genes in the progeny of transgenic maize plants. Bio/Technology 8:833-839.

Gayen, D., Sarkar, S.N., Datta, S.K., Datta, K. 2013. Comparative analysis of nutritional compositions of transgenic high iron rice with its non-transgenic counterpart. Food Chem. 138:835-840.

Hambidge, K.M., Huffer, J.W., Raboy, V., Grunwald, G.K., Westcott, J.L., Sian, L., Miller, L.V., Dorsch, J.A., Krebs. N.F. 2004. Zinc absorption from low-phytate hybrids of maize and their wild-type is hybrids. Amer. J. Clinical Nutr. 79:1053-1059.

Hammond, B., Dudek, R., Lemen, J., Nemeth, M. 2004. Results of a 13-week safety assurance study with rats fed grain from glyphosate tolerant corn. Food Chem. Toxicol. 42:1003-1014.

Hammond, B., Lemen, J., Dudek, R. 2006. Results of a 90-day safety assurance study with rats fed grain from corn rootworm-protected corn. Food Chem. Toxicol. 44:147-160.

Han, J.H., Yang, Y.X., Chen, S., Wang, Z., Yang, X.L., Wang, G.D., Men, J.H. 2005. Comparison of nutrient composition of parental rice and rice genetically modified with cowpea trypsin inhibitor in China. J. Food Comp. Anal. 18:297-302.

He, X.Y., Huang, X.Y., Li, K.L., Qin, W., Delaney, B., Luo, Y.B. 2008. Comparison of grain from corn rootworm resistant transgenic DAS-59122-7 maize with non transgenic maize grain in a 90-day feeding study in Sprague-Dawley rats. Food and Chemical Toxicol. 46:1994-2002.

Herman, R.A., Chassy, M.B., Parrott, W. 2009. Compositional assessment of transgenic crops: an idea whose time has passed. Trends in Biotechnology 27:555-557.

Hong, B., Uknes, S.J., Ho, T-HD. 1988. Cloning and characterization of a cDNA encoding an mRNA rapidly induced by ABA in barley aleurone layers. Plant Mol. Biol. 11:495-506.

Hruskova, M., Bednarova, M., Novotny, F. 2001. Wheat flour dough rheological characteristics predicted by NIR system 6500. Czech J. Food Sci. 19:213-218.

Jiang, X.L., Tian, J.C., Hao, Z., Zhang, W.D. 2008. Protein content and amino acid composition in grains of wheat-related species. Agric. Sci. China 7:272-279.

Kucek, L.H., Veenstra, D.L., Amnuaycheewa, P., Sorrells, M.E. 2015. A grounded guide to gluten: How modern genotypes and processing impact wheat sensitivity. Comprehensive Rev. Food Sci. Food Saf. 14:285301.

Lanning, S.P., Talbert, L.E., McNeal, F.H., Alexander, W.L., McGuire, C.F., Bowman, H., Carlson, G., Jackson, G., Eckhoff, J., Kushnak, G., Stewart, V., Stallknecht, G. 1992. Registration of 'Hi-Line' wheat. Crop Sci. 32:283-284.

Martinez-Povida, A., Molla-Bauza, M.B., Del Campo Gomis, F.J., Martinez, L.M.C. 2009. Consumer perceived risk model for the introduction of genetically modified food in Spain. Food Policy 34:519-528. 
Momma, K., Hashimoto, W., Yoon, J.H., Ozawa, S., Fukuda, Y., Kawai, S., Takaiwa, F, Utasumi, S., Murata, K. 2000. Safety assessment of rice genetically modified with soybean glycin by feeding studies in rats. Biosci. Biotechnol. Biochem. 64:1881-1886.

Oguchi, T., Onishi, M., Mano, J., Akiyama, H., Teshima, R., Futo, S., Furui, S., Kitta, K. 2010. Development of multiplex PCR method for simultaneous detection of four events of genetically modified maize: DAS59122-7, MIR604, MON863 and MON88017. Food Hygiene Saf. Sci. 51:92-100.

Oikonomou, N.A., Bakalis, S., Rahman, M.S., Krokida, M.K. 2015. Gluten index for wheat products: Main variables in affecting the value and nonlinear regression model. Inter. J. Food Prop. 18:1-11.

Perten, H., Bondesson, K., Mjorndal, A. 1992. Gluten index variation in commercial Swedish wheat samples. Cereal Foods World 37:655-660.

Pimentel, D. 2009. Energy inputs in food crop production in developing and developed nations. Energies 2:1-24.

Poulsen, M., Schröder, M., Wilcks, A., Kroghsbo, S., Lindecrona, R.H., Miller, A., Frenzel, T., Danier, J., Rychlik, M., Shu, Q., Emami, K., Taylor, M., Gatehouse, A., Engel, K.H., Knudsen, I. 2007. Safety testing of GM-rice expressing PHA-E lectin using a new animal test design. Food Chem. Toxicol. 45:364-377.

Prabhasankar, P., Harridas, R.P. 2001. Effect of different milling methods on chemical composition of whole wheat flour. Euro. Food Res. Technol. 213:465-469.

Ramadan, M.F., Elsanhoty, R.M. 2012. Lipid classes, fatty acids and bioactive lipids of genetically modified potato Spunta with Cry V gene. Food Chem. 133:1169-1176.

Rayan, M.A., Abbott, C.L. 2015. Compositional analysis of genetically modified corn events (NK603, MON88017, MON810 and MON89034 and MON88017) compared to conventional corn. Food Chem. 176:99-105.

Raybould, A., Graser, G., Hill, K., Ward, K. 2012. Ecological risk assessments for transgenic crops with combined insect-resistance traits: The example of Bt11, MIR604 maize. J. Appl. Entomol. 136:27-37.

Ridley, W.P., Sidhu, R.S., Pyla, P.D., Nemeth, M.A., Breeze, M.L., Astwood, J.D. 2002. Comparison of the nutritional profile of glyphosate-tolerant corn event NK603 with that of conventional corn (Zea mays L.). J. Agric. Food Chem. 50:7235-7243.

Schröder, M., Poulsen, M., Wilcks, A., Kroghsbo, S., Miller, A., Frenzel, T., Danier, J., Rychlik, M., Emami, K., Gatehouse, A., Shu, Q., Engel, K.H., Altosaar, I., Knudsen, I. 2007. A 90-day safety study of genetically modified rice expressing crylab protein (Bacillus thuringiensis toxin) in Wister rats. Food Chem. Toxicol. 45:339-349.

Shin, K., Suh, S., Lim, M., Woo, H., Lee, J.H., Kim, H., Cho, H. 2013. Event-specific detection system of stacked genetically modified maize by using the multiplex-PCR technique. Food Sci. Biotechnol. 22:17631772 .

Sivamani, E., Bahieldin, A., Wraith, M.J., Al-Niemi, T.E., Dyer, W., David, T., Qu, R. 2000. Improved biomass productivity and water use efficiency under water deficit conditions in transgenic wheat constitutively expressing the barley HVA1 gene. Plant Sci. 155:1-9.

Sthrestha, H.K., Hwu, K., Wang, S., Liu, L., Chang, M. 2008. Simultaneous detection of eight genetically modified maize lines using a combination of event- and construct-specific multiplex-PCR technique. J. Agric. Food Chem. 56:8962-8968.

Taylor, S.L. 1997. Food from genetically modified organisms and potential for food allergy. Environ. Toxicol. Pharmacol. 4:121-126.

Turkec, A.S., Lucas, J.S., Karacanli, B., Baykut, A., Yuksel, H. 2016. Assessment of a direct hybridization microarray strategy for comprehensive monitoring of genetically modified organisms (GMOs). Food Chem. 194:399-409.

Vaiciulyte-Funk, L., Grazina, Juodeikiene, G., Bartkiene, E. 2015. The relationship between wheat baking properties, specific high molecular weight glutenin components and characteristics of varieties. ZemdirbysteAgriculture 102:229-238.

World Health Organisation (WHO) 1991. Report of a Joint FAO/WHO Consultation, World Health Organisation. Geneva, Switzerland.

World Health Organisation (WHO) 1995. Report of a WHO Workshop. World Health Organisation, Food Safety Unit. Geneva, Switzerland. 
Wu, X., Zhao, R., Wang, D., Bean, S.R., Seib, P.A., Tuinstra, M.R., Campbell, M., O’Brien, A. 2006. Effects of amylose, corn protein, and corn fiber contents on production of ethanol from starch-rich media. Cereal Chem. 83:569-575.

Yoke-Kqueen, C., Yee-Tyan, C., Siew-Ping, K., Son, R. 2011. Development of multiplex-PCR for Genetically Modified Organism (GMO) detection targeting EPSPS and Cry1 Ab genes in soy and maize samples. Inter. Food Res. J. 18:515-522.

\section{Electronic Supplementary Material (ESM)}

Electronic Supplementary Material (ESM) associated with this article can be found at the website of CRC at http://www.akademiai.com/content/120427/

Electronic Supplementary Table S1. Composition of GMW and non-GMW (g/100 g dry weight)

Electronic Supplementary Table S2. Minerals content of dried wheat grains (mg/100 g) from GMW and non-GMW

Electronic Supplementary Table S3. Amino acid profile of GMW and non-GMW

Electronic Supplementary Table S4. Fatty acids profile of GMW and non-GMW

Electronic Supplementary Table S5. Wet gluten, dry gluten and gluten index profile of GMW and non-GMW

Electronic Supplementary Table S6. Farinogram properties of dough's made from GMW and non-GMW flour samples

Electronic Supplementary Table S7. Extensogram properties of dough made from GMW and non-GMW flour samples

Electronic Supplementary Figure S1. Map of the plant expression vector pAB1. The vector based on plasmid pAHC17 with barley $H V A 1$ gene driven by the maize ubil promoter region and terminated by the NOS gene $3 \%$ non-translated region. The bar gene used as the selective marker (Sivamani et al. 2000). Abbreviations for restriction sites: B, BamH1; E, EcoRI; H, HindIII; and N, NcoI

Electronic Supplementary Figure S2. Farinograms of flours (82\% extract) from GMW and non-GMW

Electronic Supplementary Figure S3. Extensogram of flours (82\% extract) from GMW and non-GMW 